\title{
Ameliorating Impact of Prophylactic Intranasal Oxytocin on Signs of Fear in a Rat Model of Traumatic Stress
}

\section{Micah D. Renicker, Nicholas Cysewski, Samuel Palmer, Dmytro Nakonechnyy, Andrew Keef, Morgan Thomas, Krisztian Magori and David P. Daberkow*}

Department of Biology, Eastern Washington University, Cheney, WA, United States

Oxytocin treatment reduces signs of long-term emotional stress after exposure to trauma; however, little is known about the potential protective effects of oxytocin treatment on behavioral and physiological changes associated with extreme stress exposure. The objective of this study was to investigate oxytocin treatment as a prophylactic measure against rat signs of fear. Two separate experiments were conducted in which the time of intranasal oxytocin administration differed. Intranasal oxytocin $(1.0 \mu \mathrm{g} / \mathrm{kg})$ was administered $5 \mathrm{~min}$ after daily exposure to foot shock in Experiment \#1 and $1 \mathrm{~h}$ before foot shock in Experiment \#2. In Experiment \#1, possible massage-evoked oxytocin release ( 5 min after foot shock) was also investigated. In both experiments, a contextual fear conditioning procedure was employed in which stress was induced via inescapable foot shock ( 3 days, 40 shocks/day, $8 \mathrm{~mA} /$ shock) in a fear conditioning chamber. Male Sprague-Dawley rats $(n=24)$ were divided into four groups ( $n=6$, per group) for each experiment. Experiment \#1 groups: Control Exp\#1 (intranasal saline and no foot shock); Stress Exp\#1 (intranasal saline 5 min after foot shock); Massage+Stress Exp\#1 (massage-like stroking and intranasal saline 5 min after foot shock); Oxytocin+Stress Exp\#1 (intranasal oxytocin 5 min after foot shock). Experiment \#2 groups: Control Exp\#2 (intranasal saline and no foot shock); Stress Exp\#2 (intranasal saline $1 \mathrm{~h}$ before foot shock); Oxytocin Exp\#2 (intranasal oxytocin and no foot shock); Oxytocin+Stress Exp\#2 (intranasal oxytocin $1 \mathrm{~h}$ before foot shock). One week after fear conditioning (and other treatments), rats were independently evaluated for behavioral signs of fear. Two weeks after conditioning, physiological signs of fear were also assessed (Experiment \#1). Relative to controls, rats treated with intranasal oxytocin 5 min after daily foot shock sessions exhibited significantly less immobility upon re-exposure to the shock chamber and attenuated physiological responses related to fear (e.g., elevated heart rate and blood pressure). Furthermore, intranasal oxytocin treatment given $1 \mathrm{~h}$ before daily foot shock sessions significantly decreased immobility and defecation upon re-exposure to the shock chamber, relative to controls. The results of this study suggest that prophylactic intranasal oxytocin, administered contemporaneously with aversive stimuli, mitigates behavioral and physiological responses associated with traumatic stress.

Keywords: oxytocin, intranasal, stress, fear, PTSD 


\section{INTRODUCTION}

Oxytocin is a neurohormone produced by neurons of the paraventricular and supraoptic nuclei in the hypothalamus. It influences a variety of social and reproductive behaviors (Donaldson and Young, 2008; Lee et al., 2009; Campbell, 2010; Meyer-Lindenberg et al., 2011; Love, 2014). Administered after traumatization, oxytocin reduces signs associated with stress in human clinical trials (Fischer-Shofty et al., 2010; Olff et al., 2010, 2013; Acheson et al., 2013; Bakermans-Kranenburg and van IJzendoorn, 2013; Stevens et al., 2013; Koch et al., 2014; MacDonald and Feifel, 2014; Nawijn et al., 2016; Sack et al., 2017), as well as in rodent studies (Missig et al., 2010; Ayers et al., 2011; Eskandarian et al., 2013; Zoicas et al., 2014; Janezic et al., 2016). However, the efficacy of oxytocin as a prophylactic, or preventive, treatment on lasting signs of stress has been less explored in humans (Frijling et al., 2014; Ostrowski and Delahanty, 2014; van Zuiden et al., 2017) and there is a dearth of related research with rodents.

Intranasal administration of oxytocin is an effective therapeutic delivery method in humans (Guastella et al., 2010; Acheson et al., 2013; Veening and Olivier, 2013; Nawijn et al., 2016; Sack et al., 2017; van Zuiden et al., 2017). Intranasal oxytocin administration has also been shown to impact specific brain areas considered "social" regions (Bethlehem et al., 2013). While the mechanisms are not clearly understood, intranasal oxytocin administration increases oxytocin levels in the cerebrospinal fluid (Chang et al., 2012; Neumann et al., 2013; Striepens et al., 2013). Oxytocin is a small peptide of nine amino acids (a nonapeptide) and it has been suggested that it may partially pass through the blood brain barrier (Ermisch et al., 1985). However, oxytocin administered intranasally is thought to bypass the blood brain barrier (Talegaonkar and Mishra, 2004; Wu et al., 2008) and therefore produces higher levels of oxytocin in the brain than can be accomplished via peripheral administration (Neumann et al., 2013). Research suggesting that intranasal administration of oxytocin directly and effectively impacts brain function warrants further investigation into its potential therapeutic effects, including any effects on conditions produced by exposure to extreme stress.

Stress alters the normal physiological equilibrium. Chronic foot shock conditioning in rodents induces lasting alterations in behaviors relating to fear and threat of aversive stimuli (LeDoux, 2000, 2014). The hallmark of these stress-induced behavioral changes is an increase in motionless periods ("freezing") upon re-exposure to the context in which the stressful stimuli were delivered, the foot shock chamber (Sahraei et al., 2012; Yu et al., 2012; Gao et al., 2014). Another sign of fear in rodents is increased defecation when re-exposed to stress-inducing stimuli (Lester, 1968; Stam et al., 1995; Gao et al., 2011). Increased defecation ("colonic motility") is a measure highly sensitive to psychological stress in rats (Verleye and Gillardin, 2004). Furthermore, many studies have demonstrated fear-related changes in cardiovascular function in rodents (Young and Leaton, 1994; Baudrie et al., 1997; Zhang et al., 2004; Liu et al., 2013, 2014). The purpose of this study was to investigate the effects of oxytocin treatment as a preventive measure against behavioral (e.g., freezing and defecation) and physiological (e.g., resting heart rate and blood pressure) signs of fear in a rat model of traumatic stress. The hypothesis is that prophylactic oxytocin treatment, administered 5 min after (Experiment \#1) or $1 \mathrm{~h}$ before (Experiment \#2) contextual fear conditioning, attenuates behavioral and physiological signs of fear in the rat.

\section{MATERIALS AND METHODS}

\section{Experiment \#1-Animals}

Sprague-Dawley rats (male, 4-5 months, $\sim 400 \mathrm{~g}$ ) were divided into four groups ( $n=6$, per group). Experiment \#1 groups: Control Exp\#1 (intranasal saline administration and no foot shock); Stress Exp\#1 (intranasal saline administration $5 \mathrm{~min}$ after foot shock); Massage+Stress Exp\#1 (massage-like stroking and intranasal saline administration 5 min after foot shock); Oxytocin+Stress Exp\#1 (intranasal oxytocin administration $5 \mathrm{~min}$ after foot shock). Rats were housed (two per cage, according to groups) with free access to food/water and kept on a $12 \mathrm{~h}$ alternating light/dark schedule. All rats were conditioned to procedural human handling for 1.5 weeks prior to the treatments and fear conditioning.

\section{Experiment \#1-Fear Conditioning}

Signs of fear were induced via a contextual fear conditioning paradigm employing inescapable foot shocks (Sahraei et al., 2012; Yu et al., 2012; Gao et al., 2014; Janezic et al., 2016). The foot shock was administered in typical fear conditioning shock chamber (the "context"), a closed Plexiglas ${ }^{\circledR}$ box $(1 \mathrm{ft} \times 1 \mathrm{ft})$ with a metal grate floor. The metal floor was connected to a transformer dial which controlled the intensity of the electric shock administered to the rat through the metal floor. Electrical shocks ( $8 \mathrm{~mA}$ intensity) were administered 20 times per session, with a duration of $3 \mathrm{~s}$ per shock, at various time intervals ranging from $7.5 \mathrm{~s}$ to $15 \mathrm{~s}$ with an approximate mean interval of $10 \mathrm{~s}$. Rat groups receiving foot shock were subjected to two such fear conditioning sessions per day, morning and afternoon (at 3-4 h intervals), for three consecutive days. The rat groups not receiving foot shock were placed in the fear condition chamber for the same time durations on the same days, but without administration of electric foot shock.

\section{Experiment \#1-Oxytocin Treatments}

Intranasal oxytocin (VetOne ${ }^{\circledR}$ ), or massage treatment, was administered during the 3 days of the fear conditioning procedure. Oxytocin+Stress Exp\#1 received intranasal administration of oxytocin $(1.0 \mu \mathrm{g} / \mathrm{kg}$; Ayers et al., 2011; Neumann et al., 2013) 5 min following the last foot shock on each day of the 3 days. Rat groups not treated with oxytocin received an equivalent intranasally administered volume $(\mu \mathrm{L})$ of saline. Prior to oxytocin (or saline) administration, rats were lightly anesthetized with isoflurane (4 min) to briefly sedate them and allow for efficient intranasal administration of the oxytocin (or saline). Once anesthetized, rats were cradled in a supine position and administered oxytocin $(1.0 \mu \mathrm{g} / \mathrm{kg})$, or an equivalent volume of saline, within $1 \mathrm{~min}$. The exact administration volume 
was determined each day according to individual rat weight, but the approximate total administration volume was $\sim 7.5 \mu \mathrm{L}$, of which half $(\sim 3.75 \mu \mathrm{L})$ was administered into each nostril via micropipette. Immediately following the intranasal saline administration, Massage+Stress Exp\#1 underwent a massage procedure (all other rats were returned to their home cages). Before returning to their home cages, Massage+Stress Exp\#1 rats were cradled across the scapula and neck region while subjected to massage-like stroking, which consisted of $5 \mathrm{~min}$ of light-pressure, abdominal stroking at approximately $20 \mathrm{~cm} / \mathrm{s}$ (Lund et al., 2002).

\section{Experiment \#1-Behavioral Measures}

Rats were individually placed back into the foot shock chamber (the "context") for $3 \mathrm{~min}$, but not shocked, to record fear-related behaviors 7 days after contextual fear conditioning. Fear memory in rats is often expressed and measured by an increase in freezing behavior (motionless periods defined as the absence of all movements except for those related to respiration; Gao et al., 2014) when reintroduced to the foot shock chamber. Freezing behavior was recorded on video for later analysis. The foot shock chamber was thoroughly cleaned (Oxivir ${ }^{\circledR}$ disinfectant) after each re-exposure.

To assess anxiety, rats were individually placed in an elevated zero maze for 5 min 11 days after fear conditioning. The elevated zero maze consisted of an annular platform elevated $65 \mathrm{~cm}$ above the floor (105 cm in diameter, $10 \mathrm{~cm}$ in width). The platform of the elevated zero maze was divided into four segments: two opposing open segments with no walls, and two opposing closed segments with walls extending $27 \mathrm{~cm}$ above the platform surface. Each rat was placed in one of the open segments of the zero maze and exploratory behavior was recorded on video for later analysis. The amount of time spent in the open segments of the zero maze was measured, which is suggested to be inversely related to the anxiety level of the animal, as proposed by Shepherd et al. (1994).

\section{Experiment \#1-Physiological Measures}

Heart rates and hematocrit levels were recorded 14 days after fear conditioning. Rats were cradled and heart rates were measured using a PowerLab 4/20T with LabChart 5 data recording software (ADInstruments). Hematocrit levels were also assessed because there is a relationship between chronically elevated blood pressure and elevated hematocrit levels (Mandal et al., 1993; Milanovic et al., 2012). Though indirect, this provides a physiological measure of blood pressure that is both easier to obtain and potentially more reliable than cumbersome blood pressure monitoring equipment typically designed to attach to an individual rat's tail. Hematocrit levels were measured from blood samples obtained by pricking the tip of the rats' tails and collecting blood in microcapillary tubes, which were subsequently centrifuged for $60 \mathrm{~s}$ (Mandal et al., 1993; Abatan et al., 2008; Milanovic et al., 2012).

\section{Experiment \#2-Animals}

Sprague-Dawley rats (male, 2-3 months, $\sim 250 \mathrm{~g}$ ) were divided into 4 groups ( $n=6$, per group). Experiment \#2 groups: Control
Exp\#2 (intranasal saline administration and no foot shock); Stress Exp\#2 (intranasal saline administration $1 \mathrm{~h}$ before foot shock); Oxytocin Exp\#2 (intranasal oxytocin administration and no foot shock); Oxytocin+Stress Exp\#2 (oxytocin administration $1 \mathrm{~h}$ before foot-shock). All rats were housed (2 per cage, according to groups) with free access to food/water and kept on a $12 \mathrm{~h}$ alternating light/dark schedule. Rats were conditioned to procedural human handling for 2-3 weeks prior to the treatments and fear conditioning.

\section{Experiment \#2-Fear Conditioning}

Signs of fear were induced via the same 3-day contextual fear conditioning procedure employed in Experiment \#1; however, in Experiment \#2, the first foot shock session was conducted $1 \mathrm{~h}$ after intranasal oxytocin administration to investigate the impact of pretreatment on signs of fear.

\section{Experiment \#2-Oxytocin Treatment}

One hour prior to fear conditioning, the rats were lightly anesthetized and treated with intranasal oxytocin $(1.0 \mu \mathrm{g} / \mathrm{kg})$, or saline, as described in Experiment \#1. Massage was not investigated in Experiment \#2; instead, a group was added in which the rats were treated with intranasal oxytocin without exposure to foot shock (Oxytocin Exp\#2).

\section{Experiment \#2-Behavioral Measures}

Seven days after fear conditioning (and other treatments), motionless periods (freezing) upon re-exposure to the foot shock chamber was assessed as described in Experiment \#1, except the rats were re-exposed to the foot shock chamber for 5 min (2 min longer than the $3 \mathrm{~min}$ re-exposure time used in Experiment \#1). Additionally, defecation upon re-exposure to the foot shock chamber was assessed in Experiment \#2. After each re-exposure to the foot shock chamber, the rat's fecal production was collected and weighed. Subsequently, the foot shock chamber was thoroughly cleaned (Oxivir ${ }^{\circledR}$ disinfectant).

\section{Statistical Analysis}

Statistical analysis on the data from Experiments \#1 and \#2 was performed using $\mathrm{R}$ software (version 3.2.3) for Windows. In Experiment \#1, all data were analyzed with a one-way analysis of variance (ANOVA) followed by a post hoc Tukey's HSD test for multiple comparisons. Student's $t$-tests were also employed on the zero maze and heart rate data to further evaluate specific differences between groups for these measures. In Experiment \#2, all data were analyzed with a two-way ANOVA followed by a post hoc Tukey's HSD test for multiple comparisons.

\section{Ethics Statement}

All experimental procedures were approved by Eastern Washington University's Institutional Animal Care and Use Committee (IACUC, protocols \#2015-01-06 and \#2016-05-01) in accordance with the recommendations of the PHS Policy on Humane Care and Use of Laboratory Animals and the Animal Welfare Act. 


\section{RESULTS}

In Experiment \#1, intranasal oxytocin treatment given 5 min after foot shock significantly reduced behavioral signs of fear. One-way ANOVA revealed an overall significant effect on ambulation (inverse of freezing behavior) $\left(F_{(3,20)}=4191.1\right.$, $p<0.0001)$. Tukey's post hoc comparisons revealed significant differences in freezing time between groups (Figure 1A): Control Exp\#1 demonstrated significantly more ambulation (less freezing) vs. Stress Exp\#1 $(p<0.01)$, Massage + Stress Exp\#1 $(p<0.01)$ and Oxytocin + Stress Exp\#1 $(p<0.01)$. Interestingly, there was significantly more ambulation in Oxytocin + Stress Exp\#1 vs. Stress Exp\#1 $(p<0.01)$ suggesting that prophylactic intranasal oxytocin treatment alleviates the stress-induced freezing response.

Anxiety was also assessed in Experiment \#1. The one-way ANOVA on measures of anxiety (time spent in the open areas of the zero maze) revealed overall significance $\left(F_{(3,20)}=3.27\right.$, $p=0.043)$. Tukey's post hoc comparisons between groups did not reveal significant differences; therefore, unpaired Student's $t$-tests were used, which revealed significant differences in measures of anxiety between groups. Oxytocin + Stress Exp\#1 spent significantly more time in the open segments of the zero maze vs. Control Exp\#1 $(p=0.046)$ and Stress Exp\#1 $(p=0.041)$. Unfortunately, Control Exp\#1 did not exhibit the expected high level of exploratory behavior into the open segments, possibly due to temporary sound pollution from the adjacent room (exclusively present during Control Exp\#1 testing); because of the uncontrolled variable (sound pollution) during this phase of zero maze data collection, the zero maze data were deemed inconclusive (data not shown).

In addition to intranasal oxytocin's significant impact on freezing behavior related to fear, it also had significant effects on physiological signs of fear investigated in Experiment \#1. Oxytocin attenuated the stress-induced elevation in hematocrit (indirect measure of blood pressure, Mandal et al., 1993; Milanovic et al., 2012) and heart rate. The one-way ANOVA revealed an overall significant difference in hematocrit $\left(F_{(3,20)}=3.54, p=0.033\right)$ and heart rates $\left(F_{(3,20)}=3637.5, p<0.0001\right)$. Tukey's post hoc comparisons revealed significant differences in hematocrit (Figure 1B). Interestingly, hematocrit values were significantly lower in Oxytocin+Stress Exp\#1 vs. Stress Exp\#1 $(p<0.05)$. Tukey's post hoc comparisons did not reveal significant differences in heart rates between groups; therefore, unpaired Student's $t$-tests were used (Figure 1C) which revealed that heart rate was significantly lower in Control Exp\#1 vs. Stress Exp\#1 $(p=0.013)$. Furthermore, Student's $t$-test revealed heart rate was significantly lower in Oxytocin+Stress Exp\#1 vs. Stress Exp\#1 $(p=0.030)$. Overall, these data suggest that intranasal oxytocin treatment prophylactically alleviates physiological signs of fear.

In Experiment \#2, intranasal oxytocin pretreatment $(1 \mathrm{~h}$ prior to shock) significantly diminished the freezing behavior of stressed rats. The two-way ANOVA revealed that stress had a significant effect on ambulation $\left(F_{(1,20)}=74.97\right.$,



B

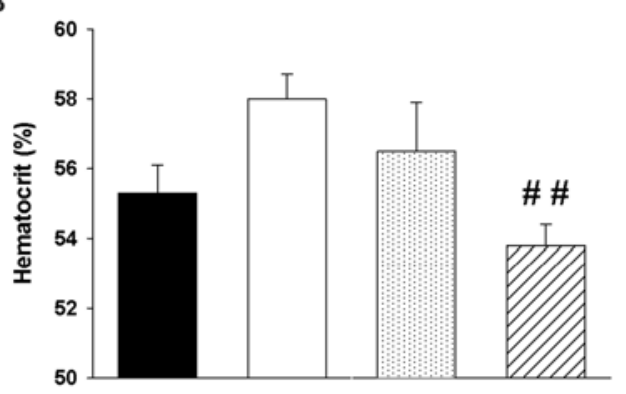

C

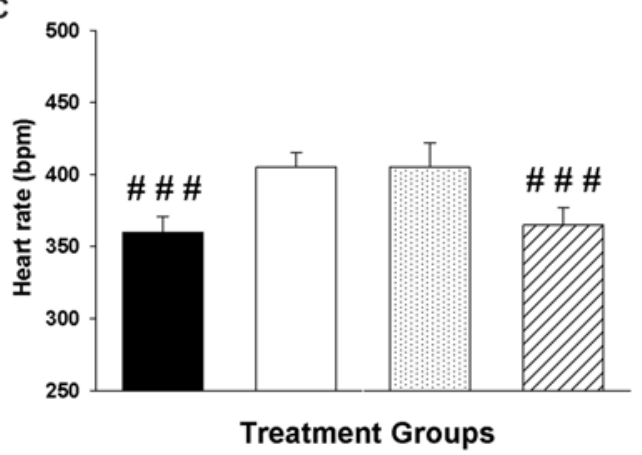

FIGURE 1 | Impact of intranasal oxytocin administered 5 min after (Experiment \#1) daily foot shock sessions (3 days, 40 shocks/day, 8 $\mathrm{mA} / \mathrm{shock}$ ). (A) Ambulation (inverse of freezing behavior) during $3 \mathrm{~min}$ re-exposure to the fear conditioning chamber 7 days after the last day of foot shock. (B) Hematocrit levels (indirect assessment of blood pressure) taken 14 days after the last day of foot shock. (C) Resting heart rate monitored 14 days after the last day of foot shock. Data analyzed by one-way analysis of variance (ANOVA) followed by post hoc Tukey's HSD test for between-group comparisons (Student's $t$-tests were used to further assess between-group comparisons of heart rates). *Significantly different than Stress Exp\#1, Massage+Stress Exp\#1 and Oxytocin+Stress Exp\#1 $(p<0.05)$. "Significantly different than Control Exp\#1, Stress Exp\#1 and Massage+Stress Exp\#1 $(p<0.05)$. \#\# Significantly different than Stress Exp\#1 $(p<0.05)$. \#\#\# Significantly different than Stress Exp\#1 ( $p<0.05, t$-test). Bars are means \pm SEM (note, all Control Exp\#1 rats were ambulatory the entire $180 \mathrm{~s}$ of testing).

$p<0.0001)$, oxytocin also had a significant effect on ambulation $\left(F_{(1,20)}=6.02, p=0.023\right)$, and there was a significant interaction between stress and oxytocin $\left(F_{(1,20)}=7.23, p=0.014\right)$. Tukey's post hoc comparisons revealed significant differences in ambulation between groups (Figure 2A): Control Exp\#2 demonstrated significantly more ambulation (less freezing) vs. Stress Exp\#2 $(p<0.0001)$ and Oxytocin + Stress Exp\#2 $(p<0.002)$. Moreover, in corroboration with Experiment \#1, there was significantly more ambulation in Oxytocin+Stress Exp\#2 vs. 

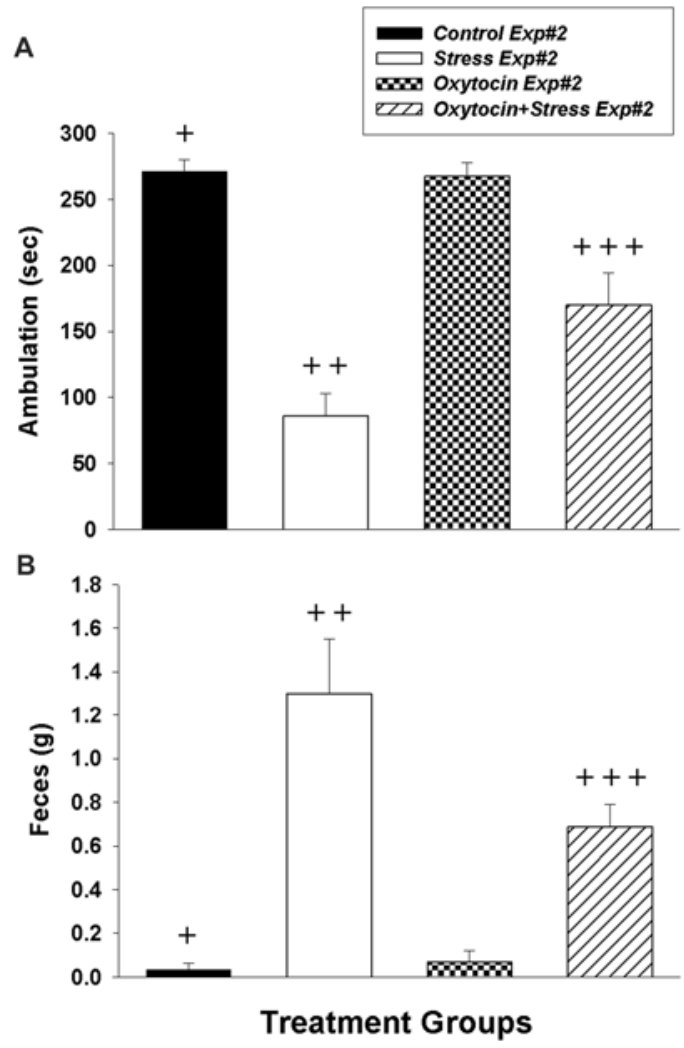

FIGURE 2 | Impact of intranasal oxytocin administered $1 \mathrm{~h}$ before (Experiment \#2) daily foot shock sessions (3 days, 40 shocks/day, $8 \mathrm{~mA} /$ shock). (A) Ambulation (inverse of freezing behavior) during $5 \mathrm{~min}$ re-exposure to the fear conditioning chamber 7 days after the last day of foot shock. (B) Fecal production (colonic motility) during the same 5 min re-exposure. Data analyzed by two-way ANOVA followed by post hoc Tukey's HSD test for between-group comparisons. + Significantly different than Stress Exp\#2 and Oxytocin+Stress Exp\#2 $(p<0.05) .{ }^{++}$Significantly different than Control Exp\#2, Oxytocin Exp\#2 and Oxytocin+Stress Exp\#2 $(p<0.05)$.

+++ Significantly different than Stress Exp\#2, Oxytocin Exp\#2 and Oxytocin+Stress Exp\#2 $(p<0.05)$. Bars are means \pm SEM.

Stress Exp\#2 $(p<0.008)$, further substantiating the mitigating effects of prophylactic intranasal oxytocin treatment on freezing behavior.

In addition to the prophylactic effects of oxytocin on freezing behavior, it also had a significant impact on stress-induced defecation, investigated in Experiment \#2. The two-way ANOVA revealed that stress had a significant effect on fecal production $\left(F_{(1,20)}=45.88, p<0.0001\right)$, oxytocin's effect on fecal production was close to significance $\left(F_{(1,20)}=4.27, p=0.052\right)$, and there was a significant interaction between stress and oxytocin $\left(F_{(1,20)}=5.42\right.$, $p=0.031)$. Tukey's post hoc comparisons between groups revealed significant differences in fecal production (Figure 2B): Control Exp\#2 demonstrated significantly less fecal production vs. Stress Exp\#2 $(p<0.0001)$ and Oxytocin+Stress Exp\#2 $(p<0.016)$. Consistent with oxytocin's effect of decreasing the freezing behavior of stressed rats, there was significantly less fecal production in Oxytocin+Stress Exp\#2 vs. Stress Exp\#2 $(p<0.026)$.

\section{DISCUSSION}

\section{Rodent Model of Traumatic Stress}

Modeling neuropsychiatric conditions, such as post-traumatic stress disorder (PTSD), is challenging (reviewed in Deslauriers et al., 2018). Resulting from exposure to psychologically traumatizing events, PTSD is characterized by a constellation of symptoms including intrusion, avoidance, alterations in mood and hyperarousal (American Psychiatric Association, 2013). Many different types of "traumatic stressors" are thought to induce PTSD in humans (Stein et al., 2014); in rodents, however, a common model of "traumatic stress" is based on the chronic electric foot shock fear conditioning paradigm (Sahraei et al., 2012; Yu et al., 2012; Gao et al., 2014; Janezic et al., 2016). Foot shock is the most common aversive stressor used in rodent fear models (Bali and Jaggi, 2015; Flandreau and Toth, 2017; Deslauriers et al., 2018). Although foot shock is not considered ethologically valid, as foot shock does not underlie the development of psychological disorders in humans, it is a physical stressor with emotional components (Bali and Jaggi, 2015). Chronic foot shock conditioning induces lasting alterations in behaviors related to stress and the emotion of fear; however, there is risk in anthropomorphizing rodent models of fear into the conceptualization of human disorders such as PTSD (LeDoux, 2014). That being said, the neural circuits and cellular/molecular mechanisms underlying the acquisition and expression of the conditioned fear response have been characterized and are conserved among mammals (Fanselow and Poulos, 2005; Maren, 2005; Johansen et al., 2011), suggesting mechanistic validity of the model. Pharmacological studies have demonstrated that fluoxetine (Siegmund and Wotjak, 2007) and paroxetine (Shimizu et al., 2004) ameliorate signs of stress in rodents, suggesting predictive validity. Furthermore, some of the core features of PTSD are present after foot shock conditioning (e.g., sleep disturbances, cognitive deficits and avoidance behavior after the traumatic event), suggesting face validity (Bali and Jaggi, 2015). Therefore, the attenuating effects of prophylactic intranasal oxytocin on signs of fear in the rat, demonstrated in this study, may have implications for certain psychiatric conditions such as PTSD.

\section{Fear Neurocircuitry and Oxytocin}

Oxytocin is a neuropeptide that directly interacts with oxytocin receptors in specific parts of the central nervous system; as such, it is considered a neuromodulator in brain regions associated with fear, aggression and social behaviors (Heinrichs and Domes, 2008; Febo and Ferris, 2014). Oxytocin receptors are expressed in the amygdala, a brain area involved in the processing of emotion and cognition (reviewed in Phelps, 2006). Furthermore, oxytocin receptors are also found in reward processing areas of the brain (Febo and Ferris, 2014), including the ventral tegmental area and the nucleus accumbens (Wise and Bozarth, 1987; Nicola, 2016). Hypothalamic oxytocin neurons have direct axonal connections to the amygdala and nucleus accumbens, and are thought to directly modulate the activity of these brain regions (MeyerLindenberg et al., 2011; Knobloch et al., 2012; Bethlehem et al., 2013). This circuitry provides a neurobiological pathway through 
which oxytocin, intranasally delivered to the brain, may alter the acquisition and expression of the behavioral signs of fear observed in this study. Although intranasal oxytocin significantly reduced fear-related behaviors (freezing and defecation), the fact that intranasal oxytocin treatment did not return these response variables to baseline levels (Figures 1A, 2A,B) suggests that, at the dosage administered in this study, oxytocin is providing partial protection from the development of these fear signs and does not entirely inhibit the manifestation of fear.

\section{HPA Axis and Oxytocin}

In addition to its direct effects on brain regions associated with the processing of emotions and motivation, oxytocin also interacts with the hypothalamic-pituitary-adrenal (HPA) axis. This endocrine feedback system is implicated in both stress reactions and the regulation of many body processes (Bhatnagar et al., 2006; Stranahan et al., 2008; Hall et al., 2012; Daskalakis et al., 2013). Oxytocin has been shown to inhibit certain stress responses associated with the HPA axis, such as corticosterone release (Windle et al., 1997; Heinrichs et al., 2003; de Kloet et al., 2006). Oxytocin levels rise following stressful incidents, and higher oxytocin levels correspond to faster recovery from stress related symptoms (Engert et al., 2016). Therefore, prophylactic intranasal oxytocin treatment could potentially provide protection during stressful events via the HPA axis.

\section{Massage and Oxytocin}

Massage has been suggested to induce oxytocin release. Massage treatment in humans has been shown to increase salivary oxytocin levels (Tsuji et al., 2015) and blood oxytocin concentrations (Morhenn et al., 2012; Rapaport et al., 2012). Although massage-like stroking of rats has an anti-nociceptive effect (Agren et al., 1995; Lund et al., 2002) and decreases blood pressure (Kurosawa et al., 1995) via oxytocinergic mechanisms, the massage treatment employed in this study was not effective in reducing fear signs. Therefore, the impact of massageevoked oxytocin on alleviating signs of fear requires further investigation.

\section{Oxytocin Prophylaxis}

To our knowledge, this is the first study demonstrating that prophylactic intranasal oxytocin, administered soon (minutes)

\section{REFERENCES}

Abatan, O. I., Welch, K. B., and Nemzek, J. A. (2008). Evaluation of saphenous venipuncture and modified tail-clip blood collection in mice. J. Am. Assoc. Lab. Anim. Sci. 47, 8-15. Available online at: www.aalas.org/publications/jaalas

Acheson, D., Feifel, D., de Wilde, S., McKinney, R., Lohr, J., and Risbrough, V. (2013). The effect of intranasal oxytocin treatment on conditioned fear extinction and recall in a healthy human sample. Psychopharmacology 229, 199-208. doi: 10.1007/s00213-0133099-4

Agren, G., Lundeberg, T., Uvnäs-Moberg, K., and Sato, A. (1995). The oxytocin antagonist 1-deamino-2-D-Tyr-(Oet)-4-Thr-8-Orn-oxytocin reverses the increase in the withdrawal response latency to thermal, but not mechanical after or before aversive stimuli, attenuates signs of fear in the rat. Intranasal oxytocin given $5 \mathrm{~min}$ after daily foot shock significantly attenuated stress-induced freezing behavior and pathological increases in measures of cardiovascular function. Furthermore, intranasal oxytocin treatment $1 \mathrm{~h}$ prior to foot shock also attenuated stress-induced freezing behavior and colonic motility. Collectively these data support the hypothesis that prophylactic, or preventative, intranasal oxytocin treatment mitigates behavioral and physiological signs of fear in the rat. Various pharmaceutical and psychosocial interventions have previously been studied as potential preventive treatments for stress-related disorders in humans, such as PTSD (reviewed in Baker et al., 2009; Daskalakis et al., 2013). Most preventive measures that have been explored fall into the category of "early intervention", in which treatment is given after the traumatic event, but prior to development of related symptoms (reviewed in Birur et al., 2017). Prophylactic oxytocin may offer the same neuroprotective benefits of other treatments (Vaiva et al., 2003; Baker et al., 2009; Daskalakis et al., 2013; Morena et al., 2017) without the risks associated with long-term treatment (Baker et al., 2009). Remedial treatment after a traumatic event might be most practical, as the majority of traumatic events cannot be predicted; however, if prophylactic or contemporaneous treatments offer significant protection, these treatments could be beneficial in settings such as combat warfare, law enforcement operations and preoperative care.

\section{AUTHOR CONTRIBUTIONS}

MR and NC conceived the project idea. All authors contributed to the project development, data collection and analysis. KM assisted with the statistical analysis. DD supervised and facilitated the research. MR drafted the manuscript, with substantial contributions from DD and MT.

\section{FUNDING}

This research was supported by the Department of Biology at Eastern Washington University.

\section{ACKNOWLEDGMENTS}

The authors thank Dr. Mike Satterwhite for his help with rat care.

nociceptive stimuli following oxytocin administration or massage-like stroking in rats. Auton. Neurosci. 187, 49-52. doi: 10.1016/0304-3940(95) 11335-t

American Psychiatric Association. (2013). Diagnostic and Statistical Manual of Mental Disorders. 5th Edn. Arlington, VA: American Psychiatric Publishing, Inc.

Ayers, L. W., Missig, G., Schulkin, J., and Rosen, J. B. (2011). Oxytocin reduces background anxiety in a fear-potentiated startle paradigm: peripheral vs central administration. Neuropsychopharmacology 36, 2488-2497. doi: 10.1038/npp. 2011.138

Baker, D. G., Nievergelt, C. M., and Risbrough, V. B. (2009). Post-traumatic stress disorder: emerging concepts of pharmacotherapy. Expert Opin. Emerg. Drugs 14, 251-272. doi: 10.1517/14728210902972494 
Bakermans-Kranenburg, M. J., and van IJzendoorn, M. H. (2013). Sniffing around oxytocin: review and meta-analyses of trials in healthy and clinical groups with implications for pharmacotherapy. Transl. Psychiatry 3:e258. doi: 10.1038/tp. 2013.34

Bali, A., and Jaggi, A. S. (2015). Electric foot shock stress: a useful tool in neuropsychiatric studies. Rev. Neurosci. 26, 655-677. doi: 10.1515/revneuro2015-0015

Baudrie, V., Tulen, J. H., Blanc, J., and Elghozi, J. L. (1997). Autonomic components of the cardiovascular responses to an acoustic startle stimulus in rats. J. Auton. Pharmacol. 17, 303-309. doi: 10.1046/j.1365-2680.1997. 00465. $\mathrm{x}$

Bethlehem, R. A., van Honk, J., Auyeung, B., and Baron-Cohen, S. (2013). Oxytocin, brain physiology, and functional connectivity: a review of intranasal oxytocin fMRI studies. Psychoneuroendocrinology 38, 962-974. doi: 10.1016/j. psyneuen.2012.10.011

Bhatnagar, S., Vining, C., Iyer, V., and Kinni, V. (2006). Changes in hypothalamicpituitary-adrenal function, body temperature, body weight and food intake with repeated social stress exposure in rats. J. Neuroendocrinol. 18, 13-24. doi: $10.1111 / j .1365-2826.2005 .01375 . x$

Birur, B., Moore, N. C., and Davis, L. L. (2017). An evidence-based review of early intervention and prevention of posttraumatic stress disorder. Community Ment. Health J. 53, 183-201. doi: 10.1007/s10597-016-0047-x

Campbell, A. (2010). Oxytocin and human social behavior. Pers. Soc. Psychol. Rev. 14, 281-295. doi: 10.1177/1088868310363594

Chang, S. W., Barter, J. W., Ebitz, R. B., Watson, K. K., and Platt, M. L. (2012). Inhaled oxytocin amplifies both vicarious reinforcement and self reinforcement in rhesus macaques (Macaca mulatta). Proc. Natl. Acad. Sci. U S A 109, 959-964. doi: 10.1073/pnas.1114621109

Daskalakis, N. P., Lehrner, A., and Yehuda, R. (2013). Endocrine aspects of post-traumatic stress disorder and implications for diagnosis and treatment. Endocrinol. Metab. Clin. North Am. 42, 503-513. doi: 10.1016/j.ecl.2013. 05.004

de Kloet, C. S., Vermetten, E., Geuze, E., Kavelaars, A., Heijnen, C. J., and Westenberg, H. G. (2006). Assessment of HPA-axis function in posttraumatic stress disorder: pharmacological and non-pharmacological challenge tests, a review. J. Psychiatr. Res. 40, 550-567. doi: 10.1016/j.jpsychires.2005. 08.002

Deslauriers, J., Toth, M., Der-Avakian, A., and Risbrough, V. B. (2018). Current status of animal models of posttraumatic stress disorder: behavioral and biological phenotypes and future challenges in improving translation. Biol. Psychiatry 83, 895-907. doi: 10.1016/j.biopsych.2017.11.019

Donaldson, Z. R., and Young, L. J. (2008). Oxytocin, vasopressin, and the neurogenetics of sociality. Science 322, 900-904. doi: 10.1126/science.1158668

Engert, V., Koester, A. M., Riepenhausen, A., and Singer, T. (2016). Boosting recovery rather than buffering reactivity: higher stress-induced oxytocin secretion is associated with increased cortisol reactivity and faster vagal recovery after acute psychosocial stress. Psychoneuroendocrinology 74, 111-120. doi: 10.1016/j.psyneuen.2016.08.029

Ermisch, A., Ruhle, H. J., Landgraf, R., and Hess, J. (1985). Blood-brain barrier and peptides. J. Cereb. Blood Flow Metab. 5, 350-357. doi: 10.1038/jcbfm. 1985.49

Eskandarian, S., Vafaei, A. A., Vaezi, G. H., Taherian, F., Kashefi, A., and RashidyPour, A. (2013). Effects of systemic administration of oxytocin on contextual fear extinction in a rat model of post-traumatic stress disorder. Basic Clin. Neurosci. 4, 315-322. Available online at: bcn.iums.ac.ir

Fanselow, M. S., and Poulos, A. M. (2005). The neuroscience of mammalian associative learning. Annu. Rev. Psychol. 56, 207-234. doi: 10.1146/annurev. psych.56.091103.070213

Febo, M., and Ferris, C. F. (2014). Oxytocin and vasopressin modulation of the neural correlates of motivation and emotion: results from functional MRI studies in awake rats. Brain Res. 1580, 8-21. doi: 10.1016/j.brainres.2014. 01.019

Fischer-Shofty, M., Shamay-Tsoory, S. G., Harari, H., and Levkovitz, Y. (2010). The effect of intranasal administration of oxytocin on fear recognition. Neuropsychologia 48, 179-184. doi: 10.1016/j.neuropsychologia. 2009.09.003

Flandreau, E. I., and Toth, M. (2017). Animal models of PTSD: A critical review. Curr. Top. Behav. Neurosci. doi: 10.1007/7854_2016_65 [Epub ahead of print].
Frijling, J. L., van Zuiden, M., Koch, S. B., Nawijn, L., Goslings, J. C., Luitse, J. S., et al. (2014). Efficacy of oxytocin administration early after psychotrauma in preventing the development of PTSD: study protocol of a randomized controlled trial. BMC Psychiatry 14, 92-244X-14-92. doi: 10.1186/1471-244x14-92

Gao, Y., Li, C., Shen, J., Yin, H., An, X., and Jin, H. (2011). Effect of food azo dye tartrazine on learning and memory functions in mice and rats and the possible mechanisms involved. J. Food Sci. 76, T125-T129. doi: 10.1111/j.1750-3841. 2011.02267.x

Gao, J., Wang, H., Liu, Y., Li, Y. Y., Chen, C., Liu, L. M., et al. (2014). Glutamate and GABA imbalance promotes neuronal apoptosis in hippocampus after stress. Med. Sci. Monit. 20, 499-512. doi: 10.12659/MSM. 890589

Guastella, A. J., Einfeld, S. L., Gray, K. M., Rinehart, N. J., Tonge, B. J., Lambert, T. J., et al. (2010). Intranasal oxytocin improves emotion recognition for youth with autism spectrum disorders. Biol. Psychiatry 67, 692-694. doi: 10.1016/j.biopsych.2009.09.020

Hall, J. M., Cruser, D., Podawiltz, A., Mummert, D. I., Jones, H., and Mummert, M. E. (2012). Psychological stress and the cutaneous immune response: roles of the HPA axis and the sympathetic nervous system in atopic dermatitis and psoriasis. Dermatol. Res. Pract. 2012:403908. doi: 10.1155/2012/403908

Heinrichs, M., Baumgartner, T., Kirschbaum, C., and Ehlert, U. (2003). Social support and oxytocin interact to suppress cortisol and subjective responses to psychosocial stress. Biol. Psychiatry 54, 1389-1398. doi: 10.1016/s00063223(03)00465-7

Heinrichs, M., and Domes, G. (2008). Neuropeptides and social behaviour: effects of oxytocin and vasopressin in humans. Prog. Brain Res. 170, 337-350. doi: 10.1016/s0079-6123(08)00428-7

Janezic, E. M., Uppalapati, S., Nagl, S., Contreras, M., French, E. D., and Fellous, J. M. (2016). Beneficial effects of chronic oxytocin administration and social co-housing in a rodent model of post-traumatic stress disorder. Behav. Pharmacol. 27, 704-717. doi: 10.1097/FBP.0000000000000270

Johansen, J. P., Cain, C. K., Ostroff, L. E., and LeDoux, J. E. (2011). Molecular mechanisms of fear learning and memory. Cell 147, 509-524. doi: 10.1016/j. cell.2011.10.009

Knobloch, H. S., Charlet, A., Hoffmann, L. C., Eliava, M., Khrulev, S., Cetin, A. H., et al. (2012). Evoked axonal oxytocin release in the central amygdala attenuates fear response. Neuron 73, 553-566. doi: 10.1016/j.neuron.2011. 11.030

Koch, S. B., van Zuiden, M., Nawijn, L., Frijling, J. L., Veltman, D. J., and Olff, M. (2014). Intranasal oxytocin as strategy for medication-enhanced psychotherapy of PTSD: salience processing and fear inhibition processes. Psychoneuroendocrinology 40, 242-256. doi: 10.1016/j.psyneuen.2013. 11.018

Kurosawa, M., Lundeberg, T., Agren, G., Lund, I., and Uvnäs-Moberg, K. (1995). Massage-like stroking of the abdomen lowers blood pressure in anesthetized rats: influence of oxytocin. J. Auton. Nerv. Syst. 56, 26-30. doi: 10.1016/01651838(95)00056-7

LeDoux, J. E. (2000). Emotion circuits in the brain. Annu. Rev. Neurosci. 23, 155-184. doi: 10.1146/annurev.neuro.23.1.155

LeDoux, J. E. (2014). Coming to terms with fear. Proc. Natl. Acad. Sci. U S A 111, 2871-2878. doi: 10.1073/pnas.1400335111

Lee, H. J., Macbeth, A. H., Pagani, J. H., and Young, W. S. III. (2009). Oxytocin: the great facilitator of life. Prog. Neurobiol. 88, 127-151. doi: 10.1016/j.pneurobio. 2009.04.001

Lester, D. (1968). Two tests of a fear-motivated theory of exploration. Psychon. Sci. 10, 385-386. doi: 10.3758/bf03331573

Liu, J., Wei, W., Kuang, H., Tsien, J. Z., and Zhao, F. (2014). Heart rate and heart rate variability assessment identifies individual differences in fear response magnitudes to earthquake, free fall and air puff in mice. PLoS One 9:e93270. doi: 10.1371 /journal.pone.0093270

Liu, J., Wei, W., Kuang, H., Zhao, F., and Tsien, J. Z. (2013). Changes in heart rate variability are associated with expression of short-term and long-term contextual and cued fear memories. PLoS One 8:e63590. doi: 10.1371/journal. pone. 0063590

Love, T. M. (2014). Oxytocin, motivation and the role of dopamine. Pharmacol. Biochem. Behav. 119, 49-60. doi: 10.1016/j.pbb.2013.06.011 
Lund, I., Ge, Y., Yu, L. C., Uvnas-Moberg, K., Wang, J., Yu, C., et al. (2002). Repeated massage-like stimulation induces long-term effects on nociception: contribution of oxytocinergic mechanisms. Eur. J. Neurosci. 16, 330-338. doi: 10.1046/j.1460-9568.2002.02087.x

MacDonald, K., and Feifel, D. (2014). Oxytocin's role in anxiety: a critical appraisal. Brain Res. 1580, 22-56. doi: 10.1016/j.brainres.2014. 01.025

Mandal, A. K., Markert, R. J., and Bell, R. D. (1993). A relationship between blood pressure control, hematocrit level and renal function in treated essential hypertension. J. Clin. Pharmacol. 33, 427-432. doi: 10.1002/j.1552-4604.1993. tb04682.x

Maren, S. (2005). Synaptic mechanisms of associative memory in the amygdala. Neuron 47, 783-786. doi: 10.1016/j.neuron.2005. 08.009

Meyer-Lindenberg, A., Domes, G., Kirsch, P., and Heinrichs, M. (2011). Oxytocin and vasopressin in the human brain: social neuropeptides for translational medicine. Nat. Rev. Neurosci. 12, 524-538. doi: 10.1038/ nrn3044

Milanovic, S., Jovovic, D., Mihailovic-Stanojevic, N., and Grujic-Milanovic, J. (2012). Chronic changes of hematocrit value alter blood pressure and glomerular filtration in spontaneously hypertensive rats. Acta Veterinaria 62, 27-37. doi: 10.2298/avb1201027m

Missig, G., Ayers, L. W., Schulkin, J., and Rosen, J. B. (2010). Oxytocin reduces background anxiety in a fear-potentiated startle paradigm. Neuropsychopharmacology 35, 2607-2616. doi: 10.1038/npp. 2010.155

Morena, M., Berardi, A., Peloso, A., Valeri, D., Palmery, M., Trezza, V., et al. (2017). Effects of ketamine, dexmedetomidine and propofol anesthesia on emotional memory consolidation in rats: consequences for the development of post-traumatic stress disorder. Behav. Brain Res. 329, 215-220. doi: 10.1016/j. bbr.2017.04.048

Morhenn, V., Beavin, L. E., and Zak, P. J. (2012). Massage increases oxytocin and reduces adrenocorticotropin hormone in humans. Altern. Ther. Health Med. 18, 11-18. Available online at: www.alternative-therapies.com

Nawijn, L., van Zuiden, M., Koch, S. B., Frijling, J. L., Veltman, D. J., and Olff, M. (2016). Intranasal oxytocin enhances neural processing of monetary reward and loss in post-traumatic stress disorder and traumatized controls. Psychoneuroendocrinology 66, 228-237. doi: 10.1016/j.psyneuen.2016. 01.020

Neumann, I. D., Maloumby, R., Beiderbeck, D. I., Lukas, M., and Landgraf, R. (2013). Increased brain and plasma oxytocin after nasal and peripheral administration in rats and mice. Psychoneuroendocrinology 38, 1985-1993. doi: 10.1016/j.psyneuen.2013.03.003

Nicola, S. M. (2016). Reassessing wanting and liking in the study of mesolimbic influence on food intake. Am. J. Physiol. Regul. Integr. Comp. Physiol. 311, R811-R840. doi: 10.1152/ajpregu.00234.2016

Olff, M., Frijling, J. L., Kubzansky, L. D., Bradley, B., Ellenbogen, M. A., Cardoso, C., et al. (2013). The role of oxytocin in social bonding, stress regulation and mental health: an update on the moderating effects of context and interindividual differences. Psychoneuroendocrinology 38, 1883-1894. doi: 10.1016/j.psyneuen.2013.06.019

Olff, M., Langeland, W., Witteveen, A., and Denys, D. (2010). A psychobiological rationale for oxytocin in the treatment of posttraumatic stress disorder. CNS Spectr. 15, 522-530. doi: 10.1017/s109285290000047x

Ostrowski, S. A., and Delahanty, D. L. (2014). Prospects for the pharmacological prevention of post-traumatic stress in vulnerable individuals. CNS Drugs 28, 195-203. doi: 10.1007/s40263-014-0145-7

Phelps, E. A. (2006). Emotion and cognition: insights from studies of the human amygdala. Annu. Rev. Psychol. 57, 27-53. doi: 10.1146/annurev.psych.56. 091103.070234

Rapaport, M. H., Schettler, P., and Bresee, C. (2012). A preliminary study of the effects of repeated massage on hypothalamic-pituitary-adrenal and immune function in healthy individuals: a study of mechanisms of action and dosage. J. Altern. Complement. Med. 18, 789-797. doi: 10.1089/acm. 2011.0071

Sack, M., Spieler, D., Wizelman, L., Epple, G., Stich, J., Zaba, M., et al. (2017). Intranasal oxytocin reduces provoked symptoms in female patients with posttraumatic stress disorder despite exerting sympathomimetic and positive chronotropic effects in a randomized controlled trial. BMC Med. 15:40. doi: 10.1186/s12916-017-0801-0

Sahraei, H., Fatahi, Z., Eidi, A., Haeri-Rohani, A., Hooshmandi, Z., Shekarforoush, S., et al. (2012). Inhibiting post traumatic stress disorder (PTSD) induced by electric shock using ethanol extract of saffron in rats. J. Biol. Res. 18, 320-327. Available online at: jbiolres.biomed central.com

Shepherd, J. K., Grewal, S. S., Fletcher, A., Bill, D. J., and Dourish, C. T. (1994). Behavioural and pharmacological characterisation of the elevated "zero-maze" as an animal model of anxiety. Psychopharmacology 116, 56-64. doi: $10.1007 / \mathrm{bf} 02244871$

Shimizu, K., Sawamura, T., Nibuya, M., Nakai, K., Takahashi, Y., and Nomura, S. (2004). An animal model of posttraumatic stress disorder and its validity: effect of paroxetine on a PTSD model in rats. Nihon Shinkei Seishin Yakurigaku Zasshi 24, 283-290. Available online at: ores.su/en/journals/japanese-journalof-psychopharmacology

Siegmund, A., and Wotjak, C. T. (2007). A mouse model of posttraumatic stress disorder that distinguishes between conditioned and sensitised fear. J. Psychiatr. Res. 41, 848-860. doi: 10.1016/j.jpsychires.2006. 07.017

Stam, R., Croiset, G., Akkermans, L. M. A., and Wiegant, V. M. (1995). Effects of novelty and conditioned fear on small intestinal and colonic motility and behaviour in the rat. Physiology and Behavior 58, 803-809. doi: 10.1016/00319384(95)00137-8

Stein, D. J., McLaughlin, K. A., Koenen, K. C., Atwoli, L., Friedman, M. J., Hill, E. D., et al. (2014). DSM-5 and ICD-11 definitions of posttraumatic stress disorder: investigating "narrow" and "broad" approaches. Depress. Anxiety 31, 494-505. doi: 10.1002/da.22279

Stevens, F. L., Weisman, O., Feldman, R., Hurley, R. A., and Taber, K. H. (2013). Oxytocin and behavior: evidence for effects in the brain. J. Neuropsychiatry Clin. Neurosci. 25, 96-102. doi: 10.1176/appi.neuropsych. 13030061

Stranahan, A. M., Lee, K., and Mattson, M. P. (2008). Central mechanisms of HPA axis regulation by voluntary exercise. Neuromolecular Med. 10, 118-127. doi: 10.1007/s12017-008-8027-0

Striepens, N., Kendrick, K. M., Hanking, V., Landgraf, R., Wullner, U., Maier, W., et al. (2013). Elevated cerebrospinal fluid and blood concentrations of oxytocin following its intranasal administration in humans. Sci. Rep. 3:3440. doi: 10.1038/srep03440

Talegaonkar, S., and Mishra, P. R. (2004). Intranasal delivery: an approach to bypass the blood brain barrier. Indian J. Pharmcol. 36, 140-147. Available online at: www.ijp-online.com

Tsuji, S., Yuhi, T., Furuhara, K., Ohta, S., Shimizu, Y., and Higashida, H. (2015) Salivary oxytocin concentrations in seven boys with autism spectrum disorder received massage from their mothers: a pilot study. Front. Psychiatry 6:58. doi: $10.3389 /$ fpsyt.2015.00058

Vaiva, G., Ducrocq, F., Jezequel, K., Averland, B., Lestavel, P., Brunet, A., et al. (2003). Immediate treatment with propranolol decreases posttraumatic stress disorder two months after trauma. Biol. Psychiatry 54, 947-949. doi: 10.1016/s0006-3223(03)00412-8

van Zuiden, M., Frijling, J. L., Nawijn, L., Koch, S. B. J., Goslings, J. C., Luitse, J. S., et al. (2017). Intranasal oxytocin to prevent posttraumatic stress disorder symptoms: a randomized controlled trial in emergency department patients. Biol. Psychiatry 81, 1030-1040. doi: 10.1016/j.biopsych.2016. 11.012

Veening, J. G., and Olivier, B. (2013). Intranasal administration of oxytocin: behavioral and clinical effects, a review. Neurosci. Biobehav. Rev. 37, 1445-1465. doi: 10.1016/j.neubiorev.2013.04.012

Verleye, M., and Gillardin, J. (2004). Effects of etifoxine on stress-induced hyperthermia, freezing behavior and colonic motor activation in rats. Physiol. Behav. 82, 891-897. doi: 10.1016/j.physbeh.2004.07.010

Windle, R. J., Shanks, N., Lightman, S. L., and Ingram, C. D. (1997). Central oxytocin administration reduces stress-induced corticosterone release and anxiety behavior in rats. Endocrinology 138, 2829-2834. doi: 10.1210/en.138. 7.2829

Wise, R. A., and Bozarth, M. A. (1987). A psychomotor stimulant theory of addiction. Psychol. Rev. 94, 469-492. doi: 10.1037//0033-295x. 94.4.469 
Wu, H., Hu, K., and Jiang, X. (2008). From nose to brain: understanding transport capacity and transport rate of drugs. Expert Opin. Drug Deliv. 5, 1159-1168. doi: $10.1517 / 17425247.5 .10 .1159$

Young, B. J., and Leaton, R. N. (1994). Fear potentiation of acoustic startle stimulus-evoked heart rate changes in rats. Behav. Neurosci. 108, 1065-1079. doi: 10.1037/0735-7044.108.6.1065

Yu, H., Watt, H., Kesavan, C., Johnson, P. J., Wergedal, J. E., and Mohan, S. (2012). Lasting consequences of traumatic events on behavioral and skeletal parameters in a mouse model for post-traumatic stress disorder (PTSD). PLoS One 7:e42684. doi: 10.1371/journal.pone. 0042684

Zhang, W. N., Murphy, C. A., and Feldon, J. (2004). Behavioural and cardiovascular responses during latent inhibition of conditioned fear: measurement by telemetry and conditioned freezing. Behav. Brain Res. 154, 199-209. doi: 10.1016/j.bbr.2004.02.016
Zoicas, I., Slattery, D. A., and Neumann, I. D. (2014). Brain oxytocin in social fear conditioning and its extinction: involvement of the lateral septum. Neuropsychopharmacology 39, 3027-3035. doi: 10.1038/npp.2014.156

Conflict of Interest Statement: The authors declare that the research was conducted in the absence of any commercial or financial relationships that could be construed as a potential conflict of interest.

Copyright (C) 2018 Renicker, Cysewski, Palmer, Nakonechnyy, Keef, Thomas, Magori and Daberkow. This is an open-access article distributed under the terms of the Creative Commons Attribution License (CC BY). The use, distribution or reproduction in other forums is permitted, provided the original author(s) and the copyright owner are credited and that the original publication in this journal is cited, in accordance with accepted academic practice. No use, distribution or reproduction is permitted which does not comply with these terms. 